\title{
Association between hip muscle cross- sectional area and hip pain and function in individuals with mild-to-moderate hip osteoarthritis: a cross-sectional study
}

Waruna L. Peiris ${ }^{1}$, Flavia M. Cicuttini', Maria Constantinou², Abbas Yaqobi ${ }^{1}$, Sultana Monira Hussain ${ }^{1}$, Anita E. Wluka', Donna Urquhart ${ }^{1}$, Rod Barrett ${ }^{3}$, Ben Kennedy ${ }^{4}$ and Yuanyuan Wang ${ }^{1 *}$

\begin{abstract}
Background: To examine the associations between hip muscle cross-sectional area and hip pain and function in community-based individuals with mild-to-moderate hip osteoarthritis.

Methods: This study included 27 participants with mild-to-moderate hip osteoarthritis. Cross-sectional area of hip muscles, including psoas major, rectus femoris, gluteus maximus, gluteus medius and minimus, adductor longus and magnus, obturator internus, and obturator externus, were measured from magnetic resonance images. Hip pain and function were evaluated using the Hip Disability and Osteoarthritis Outcome Score (HOOS) categorised into 5 subscales: pain, symptoms, activity of daily living, sport and recreation function, and hip-related quality of life (for each subscale 0 representing extreme problems and 100 representing no problems).

Results: Mean age of the 27 participants was 63.2 (SD 7.6) years and 66.7\% $(n=18)$ were female. After adjusting for age and gender, greater cross-sectional area of adductor longus and magnus was associated with a higher HOOS score in quality of life (regression coefficient 1.4, 95\% confidence interval (CI) $0.2-2.7, p=0.02$ ), activity of daily living (regression coefficient $1.3,95 \% \mathrm{Cl} 0.1-2.6, p=0.04$ ) and sport and recreation function (regression coefficient 1.6, $95 \% \mathrm{Cl} 0.1-3.0, p=0.04$ ). There was a trend towards an association between greater cross-sectional area of psoas major and a higher quality of life score (regression coefficient 3.6, $95 \% \mathrm{Cl}-0.5$ to $7.7, p=0.08$ ). The cross-sectional area of hip muscles was not significantly associated with HOOS pain or symptom score.

Conclusion: Greater cross-sectional area of hip adductors was associated with better function and quality of life in individuals with mild-to-moderate hip osteoarthritis. Greater cross-sectional area of hip flexors might be associated with better quality of life. These findings, while need to be confirmed in longitudinal studies, suggest that targeting the hip adductor and flexor muscles may improve function and quality of life in those with mild-to-moderate hip osteoarthritis.
\end{abstract}

\footnotetext{
* Correspondence: yuanyuan.wang@monash.edu

'School of Public Health and Preventive Medicine, Monash University, 553 St Kilda Rd, Melbourne, VIC 3004, Australia

Full list of author information is available at the end of the article
}

C C The Author(s). 2020 Open Access This article is licensed under a Creative Commons Attribution 4.0 International License, which permits use, sharing, adaptation, distribution and reproduction in any medium or format, as long as you give appropriate credit to the original author(s) and the source, provide a link to the Creative Commons licence, and indicate if changes were made. The images or other third party material in this article are included in the article's Creative Commons licence, unless indicated otherwise in a credit line to the material. If material is not included in the article's Creative Commons licence and your intended use is not permitted by statutory regulation or exceeds the permitted use, you will need to obtain permission directly from the copyright holder. To view a copy of this licence, visit http://creativecommons.org/licenses/by/4.0/. The Creative Commons Public Domain Dedication waiver (http://creativecommons.org/publicdomain/zero/1.0/) applies to the data made available in this article, unless otherwise stated in a credit line to the data. 


\section{Background}

Osteoarthritis (OA) is one of the leading causes of disability worldwide, with disability-adjusted life years predicted to rise with the increasing age and prevalence of obesity in the population [1]. Hip OA has a life time prevalence of one in four people [2] and can be both painful and disabling, severely impacting the quality of life of an individual [3]. Current efforts to reduce the burden of hip OA include treatment for alleviation of pain and improvement of function that include exercise, weight reduction, acetaminophen, non-steroidal anti-inflammatory drugs, and intraarticular injections of corticosteroids and hyaluronates [4], with end-stage disease treated with total hip replacement.

Hip muscles are critical for movement of the trunk and legs and redistribution of segmental power when walking, and may also be important for stabilizing the hip joint $[5,6]$. The force generated by a muscle is largely a function of the muscle's physiological cross-sectional area (CSA) and the level of motor unit pool activation [7, 8]. There is evidence for generalized muscle weakness of the affected leg in people with unilateral hip OA, due to multifactorial mechanisms including a combination of reduced muscle size (atrophy), muscle inhibition, and decreased muscle quality [9]. More specifically, there is evidence of deficits in lower limb muscle strength and size in people with mild-to-moderate hip OA relative to healthy controls $[10,11]$, and biomechanical studies reported functional deficits during walking and sit-tostand in participants with mild-to-moderate hip OA compared with healthy controls $[12,13]$ and altered muscle activity during gait in people with hip OA compared with healthy controls [14]. However, there are limited data examining the associations between hip muscle properties and patientreported outcomes in pain and function. Previous studies have shown some evidence for an association between decreased hip adductor strength with groin pain $[15,16]$, and for a negative association between fiber CSA of gluteus medius muscle and hip pain [17]. These studies have only looked at a single muscle or limited groups of muscles, and investigations of a wider range of hip muscles are needed to establish a better understanding of the relationship between muscle weakness and functional outcomes in hip OA [9].

There is a need for studies to comprehensively examine hip muscles of different functional groups as possible modifiable factors for improving the management of hip OA at an early stage of the disease, where the opportunity to alter patient outcomes remains. The aim of this study was therefore to examine the associations between CSA of hip muscles of different functional groups and patient-reported hip pain and function in individuals with mild-to-moderate hip OA.

\section{Methods}

\section{Participants}

Individuals over the age of 45 years were recruited between June 2011 and October 2014 through advertisements, word of mouth, and hospital orthopaedic waiting lists. Volunteers were screened using the Harris Hip Score (HHS) [18] and radiographic examination. From 420 individuals who volunteered, 60 individuals with hip pain were eligible to complete the HHS and subsequently undergo radiographic screening evaluation for possible participation in the study. All participants were of Caucasian background. Weightbearing anterior-posterior radiographs of the pelvis and hips were performed with feet internally rotated by $15 \pm 5$ degrees [19]. An experienced radiologist electronically scored radiographs for both hips based on the KellgrenLawrence grades, and the presence of osteophytes using the Osteoarthritis Research Society International grading criteria [20], and electronically measured hip joint space width at the supero-medial, apical and supero-lateral regions.

Inclusion and exclusion criteria

Participants with hip pain in the last 3 months, HHS $\leq$ 95 points, Kellgren-Lawrence grade 2 or 3 and/or joint space width $\leq 3 \mathrm{~mm}$ in one or both hips were defined as having hip OA $(n=27)$. Individuals with KellgrenLawrence grade 4 and joint space width $<1 \mathrm{~mm}$ or any major lower limb musculoskeletal or neurological conditions besides hip OA were excluded.

Data for the affected unilateral or most affected bilateral limb of individuals with hip OA were used for statistical analysis [12]. The most affected limb in those with bilateral hip OA was determined by the least joint space width. Ethical approval was granted by Griffith University Human Research Ethics Committee (GU Ref No: PES/23/08/HREC), Queensland Health, Health and Medical Research Human Research Ethics Committee (HREC/13/QPAH/207), and Monash University Human Research Ethics Committee (10754), and all participants provided written informed consent prior to commencement of the study.

\section{Anthropometric measures}

Height was measured using a stadiometer with the removal of footwear. Weight was measured via an electronic scale with the removal of footwear and heavy clothing. Body mass index (BMI) was calculated.

\section{Hip pain and function}

Hip pain and function were evaluated using the validated Hip Disability and Osteoarthritis Outcome Score (HOOS) [21]. The HOOS is composed of 40 items and assesses patient-relevant outcomes in five subscales: pain (10 items), symptoms (5 items), activity of daily living (17 items), sport and recreation function (4 items), and hip-related quality of life (4 items). Each question is scored from 0 to 4 (5 Likert boxes). For each subscale, the scores are summarized and transformed into a worst to best scale ranging from 0 to 100 scale. Higher scores 
refer to better outcome: 0 representing extreme problems and 100 representing no problems.

\section{Hip muscle CSA and fat infiltration}

Participants underwent magnetic resonance imaging (MRI) of the pelvis and leg (starting from above iliac crest down to knee, bilateral) using a $3.0 \mathrm{~T}$ MRI unit (Phillips Healthcare Ingenia). Participants were positioned in supine position with body coil arrays superiorly placed on lower limbs and legs in $15^{\circ}$ of hip internal rotation, secured together with a strap. Hip muscle CSA was measured on axial images obtained using a T1 weighted 2-dimensional fast spin echo sequence (repetition time $731.6 \mathrm{msec}$, echo time $6.5 \mathrm{msec}$, flip angle $90^{\circ}$, slice thickness $10 \mathrm{~mm}$, pixel matrix $0.47 \mathrm{~mm} \times 0.47 \mathrm{~mm}$, and $960 \times 960$ matrix). The CSA of hip muscles was measured from five regions (Fig. 1), adapted from a previous study [22]: (a) Iliac crest: psoas major; (b) Upper border of the acetabulum: gluteus maximus, gluteus medius and gluteus minimus; (c) Lower border of the acetabulum: obturator internus; (d) Ischial tuberosity: obturator externus; (e) Just below the gluteus maximus muscle: adductor longus, adductor magnus, and rectus femoris. Muscle CSA was measured by tracing the border of each muscle using the software Osirix
(University Hospital of Geneva, Geneva, Switzerland) on an independent workstation. A reader, trained by a radiologist, who was blinded to the participant characteristics, hip pain and function, measured the hip muscle CSA twice with 1 week interval, and the average was taken as the muscle CSA. The intra-observer reproducibility (intra-class correlation coefficient) ranged from 0.78 to 1.00 . Fat infiltration of hip muscles was measured on axial images and categorised into grade 0 : no fat infiltration, grade 1: $1-10 \%$ fat infiltration, grade 2: $11-50 \%$ fat infiltration, and grade 3: $>50 \%$ fat infiltration. The intra-observer reproducibility (intra-class correlation coefficient) of our measurement was 0.99 .

\section{Statistical analysis}

Participant characteristics were tabulated. Multiple linear regression was used to examine the associations of hip muscle CSA with hip pain and function (HOOS scores) of the target hip, adjusted for age and gender. A $p$-value of less than 0.05 (two-tailed) was considered statistically significant. All statistical analyses were performed using the IBM Statistical Package for the Social Sciences (SPSS, Chicago, IL) software, version 24.
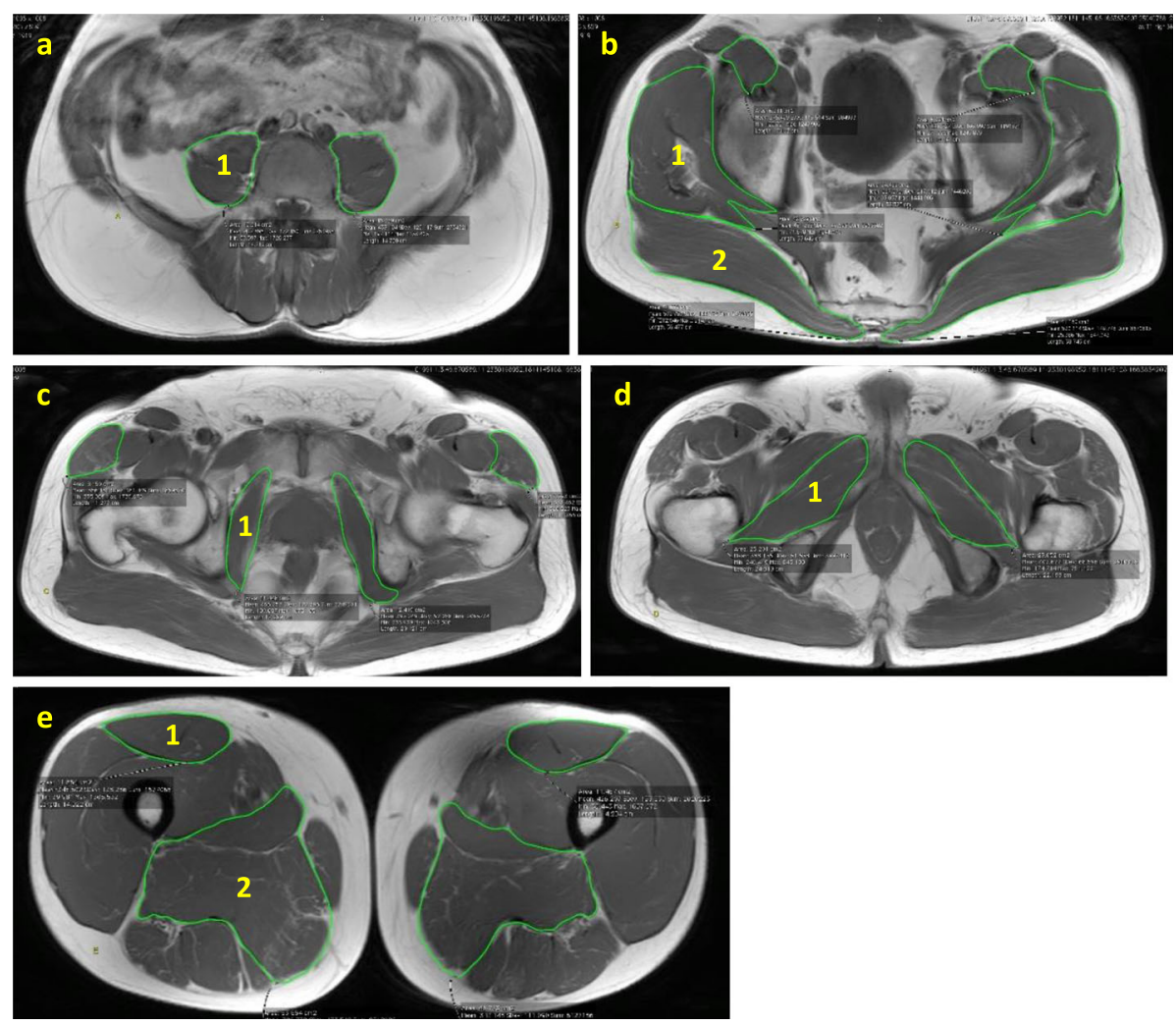

Fig. 1 Cross-sectional area measurements of (a) 1. Psoas major; (b) 1. Gluteus medius and gluteus minimus, 2. Gluteus maximus; (c) 1. Obturator internus; (d) 1. Obturator externus; (e) 1. Rectus femoris, 2. Adductor longus and adductor magnus 


\section{Results}

The characteristics of participants are shown in Table 1 . The mean age of the participants was 63.2 years with a mean BMI of $28.0 \mathrm{~kg} / \mathrm{m}^{2}$ and $66.7 \%$ being female. The mean joint space width of the study hip was $2.39 \mathrm{~mm}$, and the majority $(92.6 \%)$ of the participants had mild-tomoderate hip OA (i.e. Kellgren-Lawrence grade $\leq 3$ ).

The associations between hip muscle CSA and HOOS scores are presented in Table 2. Although the CSA of psoas major, flexors total, adductor longus and magnus was positively associated with HOOS pain score in univariable analyses, there were no significant association between the CSA of hip muscles and HOOS pain score

Table 1 Characteristics of study participants

\begin{tabular}{|c|c|}
\hline & $N=27$ \\
\hline Age, years & $63.2(7.6)$ \\
\hline Female, n (\%) & $18(66.7)$ \\
\hline Body mass index, $\mathrm{kg} / \mathrm{m}^{2}$ & $28.0(4.1)$ \\
\hline Joint space width, mm & $2.39(0.98)$ \\
\hline \multicolumn{2}{|l|}{ Kellgren-Lawrence grade, $\mathrm{n}(\%)$} \\
\hline 1 & $1(3.7)$ \\
\hline 2 & $11(40.7)$ \\
\hline 3 & $13(48.1)$ \\
\hline 4 & $2(7.4)$ \\
\hline \multicolumn{2}{|l|}{ Hip muscle cross-sectional area, $\mathrm{cm}^{2}$} \\
\hline \multicolumn{2}{|l|}{ Flexors } \\
\hline Psoas major & $13.9(3.7)$ \\
\hline Rectus femoris & $8.0(2.3)$ \\
\hline Flexors total ${ }^{a}$ & $21.8(5.7)$ \\
\hline \multicolumn{2}{|l|}{ Extensors } \\
\hline Gluteus maximus & $46.1(10.2)$ \\
\hline \multicolumn{2}{|l|}{ Adductors } \\
\hline Adductor longus and magnus & $40.3(10.8)$ \\
\hline \multicolumn{2}{|l|}{ Abductors } \\
\hline Gluteus medius and minimus & $32.4(6.9)$ \\
\hline \multicolumn{2}{|l|}{ Rotators } \\
\hline Obturator internus & $11.9(2.0)$ \\
\hline Obturator externus & $26.5(4.7)$ \\
\hline Rotators total ${ }^{\mathrm{b}}$ & $38.5(5.7)$ \\
\hline \multicolumn{2}{|l|}{ HOOS scores } \\
\hline Pain & $66.5(21.6)$ \\
\hline Symptoms & $66.7(18.6)$ \\
\hline Activity of daily living & $72.6(24.2)$ \\
\hline Sport and recreation function & $60.7(28.7)$ \\
\hline Hip-related quality of life & $52.3(25.0)$ \\
\hline
\end{tabular}

Data presented as mean (standard deviation) or $\mathrm{n}(\%)$. HOOS Hip Disability and Osteoarthritis Outcome Score

${ }^{\mathrm{a}}$ Psoas major + Rectus femoris; ${ }^{\mathrm{b}}$ Obturator internus + Obturator externus in multivariable analyses adjusted for age and gender. Greater CSA of adductor longus and magnus was associated with better hip-related quality of life in multivariable analyses (regression coefficient 1.4, 95\% confidence interval $(\mathrm{CI}) 0.2$ to $2.7, p=0.02$ ). There was a trend towards an association between greater CSA of psoas major (regression coefficient 3.6, 95\% CI -0.5 to 7.7, $p=0.08$ ) and flexors total (psoas major and rectus femoris; regression coefficient $2.3,95 \% \mathrm{CI}-0.3$ to 5.0 , $p=0.08)$ and better hip-related quality of life, achieving borderline significance. The CSA of other hip muscles was not significantly associated with hip-related quality of life.

Greater CSA of adductor longus and magnus was associated with better function in activity of daily living (regression coefficient 1.3, 95\% CI 0.1 to 2.6, $p=0.04$ ) and in sport and recreation (regression coefficient 1.6, 95\% CI 0.1 to $3.0, p=0.04$ ). The CSA of hip muscles was not significantly associated with HOOS symptom score in multivariable analyses (Supplementary Table 1).

There was low variation in the levels of fat infiltration of hip muscles, with fat infiltration of $1-10 \%$ or $11-50 \%$ (Supplementary Table 2). None of the fat infiltration variables were associated with hip pain and function outcomes in univariable linear regression analyses (all $p>$ 0.20 ). Including fat infiltration in the regression models did not change the results (data not shown).

\section{Discussion}

To our knowledge, this is the first study to examine the relationship between hip muscle CSA and hip pain and functional outcomes in community-based individuals with mild-to-moderate hip OA. There was a positive association between greater CSA of hip adductors and better function (activity of daily living and sport and recreation) and quality of life. There was also a nonsignificant trend towards an association between greater CSA of hip flexors and better quality of life. These findings suggest that targeting the hip adductor musculature in treatment may lead to improved hip function and quality of life among individuals with mild-to-moderate hip OA.

We found that greater CSA of hip adductors was associated with better functional outcomes in those with mild-to-moderate hip OA. The most significant and consistent associations were found for the hip adductors, including adductor longus and magnus. The hip adductor muscles play an important role in balancing the pelvis during standing and walking and for overall hip stability and injury prevention. Previous studies reported lower volume and CSA of hip adductor muscles and decreased hip adductor strength in people with hip OA compared with healthy controls $[10,22]$. Other studies investigating pain and injury reported a lower hip adduction/abduction 
Table 2 Relationship between hip muscle cross-sectional area and HOOS outcomes

\begin{tabular}{|c|c|c|c|c|}
\hline & $\begin{array}{l}\text { Univariable } \\
\text { Regression coefficient ( } 95 \% \text { Cl) }\end{array}$ & $P$-value & $\begin{array}{l}\text { Multivariable } \\
\text { Regression coefficient }(95 \% \mathrm{Cl})^{*}\end{array}$ & $P$-value* \\
\hline \multicolumn{5}{|l|}{ Pain } \\
\hline \multicolumn{5}{|l|}{ Flexors } \\
\hline Psoas major & $2.8(0.6,4.9)$ & 0.01 & $2.8(-0.9,6.4)$ & 0.13 \\
\hline Rectus femoris & $3.4(-0.1,7.0)$ & 0.06 & $2.4(-2.9,7.7)$ & 0.36 \\
\hline Flexors total & $1.7(0.3,3.1)$ & 0.02 & $1.7(-0.7,4.1)$ & 0.16 \\
\hline \multicolumn{5}{|l|}{ Extensors } \\
\hline Gluteus maximus & $0.5(-0.3,1.4)$ & 0.20 & $-0.03(-1.4,1.3)$ & 0.97 \\
\hline \multicolumn{5}{|l|}{ Adductors } \\
\hline Adductor longus and magnus & $0.9(0.1,1.6)$ & 0.03 & $0.9(-0.2,2.1)$ & 0.10 \\
\hline \multicolumn{5}{|l|}{ Abductors } \\
\hline Gluteus medius and minimus & $0.4(-0.8,1.7)$ & 0.48 & $-0.7(-2.6,1.2)$ & 0.45 \\
\hline \multicolumn{5}{|l|}{ Rotators } \\
\hline Obturator internus & $-0.9(-5.4,3.7)$ & 0.70 & $-0.4(-5.4,4.5)$ & 0.86 \\
\hline Obturator externus & $0.5(-1.6,2.5)$ & 0.65 & $-1.3(-3.9,1.3)$ & 0.30 \\
\hline Rotators total & $0.2(-1.5,1.9)$ & 0.84 & $-0.8(-2.7,1.2)$ & 0.41 \\
\hline \multicolumn{5}{|l|}{ Hip-related quality of life } \\
\hline \multicolumn{5}{|l|}{ Flexors } \\
\hline Psoas major & $3.3(0.9,5.7)$ & 0.01 & $3.6(-0.5,7.7)$ & 0.08 \\
\hline Rectus femoris & $4.4(0.3,8.4)$ & 0.04 & $3.8(-2.2,9.8)$ & 0.20 \\
\hline Flexors total & $2.1(0.5,3.7)$ & 0.01 & $2.3(-0.3,5.0)$ & 0.08 \\
\hline \multicolumn{5}{|l|}{ Extensors } \\
\hline Gluteus maximus & $0.9(-0.1,1.8)$ & 0.07 & $0.6(-0.9,2.2)$ & 0.39 \\
\hline \multicolumn{5}{|l|}{ Adductors } \\
\hline Adductor longus and magnus & $1.1(0.3,2.0)$ & 0.01 & $1.4(0.2,2.7)$ & 0.02 \\
\hline \multicolumn{5}{|l|}{ Abductors } \\
\hline Gluteus medius and minimus & $0.6(-0.9,2.0)$ & 0.44 & $-0.6(-2.8,1.6)$ & 0.57 \\
\hline \multicolumn{5}{|l|}{ Rotators } \\
\hline Obturator internus & $0.2(-5.1,5.4)$ & 0.95 & $1.2(-4.4,6.9)$ & 0.66 \\
\hline Obturator externus & $0.8(-1.5,3.1)$ & 0.48 & $-1.1(-4.0,1.8)$ & 0.44 \\
\hline Rotators total & $0.5(-1.4,2.4)$ & 0.61 & $-0.5(-2.6,1.7)$ & 0.66 \\
\hline
\end{tabular}

*Adjusted for age and gender

HOOS Hip Disability and Osteoarthritis Outcome Score, $\mathrm{Cl}$ confidence interval

strength ratio in soccer players with groin pain compared with those without groin pain [15] and that hip adductor strength was decreased both preceding and during the onset of groin pain in football players [16]. Although these studies investigated adductor strength rather than CSA, the findings indicate the importance of hip adductor muscles when considering pain and recovery for better function.

There was a trend that larger CSA of hip flexors would be associated with better quality of life in our study. Hip flexors are used for a variety of everyday functional activities such as advancing the lower extremity during gait, running, or lifting the leg when going up steps. Although decreased hip flexor strength has been reported in people with hip OA compared with healthy controls [10, 22], no previous studies have examined the relationship between hip flexors and hip pain or functional outcomes. While gluteal muscle atrophy (i.e. decreased muscle volume) was associated with the presence and clinical severity of hip OA [23-26], one study found a weak negative correlation between gluteus medius muscle fiber CSA and hip pain [17]. In contrast, our study did not find an association between CSA of gluteus medius and minimus muscle and hip pain or function. The gluteus medius and gluteus minimus muscles were measured together in our study, as the border between the two muscles was indistinguishable on our scans; as a result, the association between gluteus medius and hip pain or function may have been overlooked. 
There is evidence that larger CSA of hip muscles may result in greater muscle strength $[7,8,22]$ which would allow efficient force distribution within the joint and improvement of hip stability, resulting in better function. It is also plausible that better function facilitates more use and therefore larger CSA of the hip muscles. Our results suggest that there are potential muscles that could be targeted in those with hip OA to improve functional outcomes. This will need to be tested in clinical trials. Clinical guidelines for the treatment of hip OA recommend education, strength training and exercise programs [27-29]. A systematic review of 13 cross-sectional studies suggested the need to target muscle weakness in the clinical management of hip OA [9]. In persons with hip OA, the greatest reduction in muscle strength of the affected leg compared with the contralateral leg was seen for hip flexors and extensors, with less consistent data for hip adductors and abductors [9]. However, there were consistent data for lower hip abductor strength in people with hip OA compared with healthy controls [9, 10, 22-24, 30]. Adding to the literature, our study found beneficial associations of larger CSA of hip adductors with better function and quality of life in hip OA. Taken together, these data suggest that targeting these hip muscles may have significant implications for reducing the burden of hip OA in the community, where pain, disability and impaired quality of life are growing concerns in the current population.

This study had limitations. It is a cross-sectional study with a moderate sample size. Whether there is a temporal relationship between hip muscle CSA and functional outcomes could not be investigated. The moderate sample size limited the power of the study to detect an association between CSA of some hip muscles and pain and functional outcomes. The CSA of hip muscles was not significantly different between the right and left hips in the 11 participants with bilateral hip OA (data not shown). The most affected hip in participants with bilateral hip OA was the study hip for statistical analyses. The results did not change when the average CSA of right and left hip muscles were examined in those with bilateral hip OA (data not shown). Due to the lack of demarcation between muscles, some specific muscles could not be segmented individually and instead were grouped for CSA measurement, such as the adductors, and gluteus medius and gluteus minimus muscles. Identifying specific muscles could shed further light on which muscles contribute to better hip outcomes. Consistency with regards to anatomical positions for muscle CSA measurement was another issue. The slice thickness may have surpassed some regions due to the difference in terms of where the initial slice began or the difference in body size among participants. As shown in a systematic review, segmentation of CSA on a single slice increased volume errors [31]. These types of measurement errors were likely to be at random and have resulted in underestimation of the magnitude of observed associations. Furthermore, studies looking at muscle volume and adiposity are emerging areas that may provide additional information and overcome some of the limitations of examining CSA alone. We were only able to adjust for limited numbers of confounders in the statistical analyses, and we have controlled for the difference in body size by adjustment for gender. The strengths of this study include the high reproducibility of the MRI measurement of hip muscle CSA. A full-length scan from the iliac crest to the knee allowed the CSA measurement of hip muscles of different functional groups. Furthermore, there is evidence for the validity of CSA measurement of hip muscles against muscle strength and severity of hip OA [22]. HOOS is validated and well accepted in the OA scientific literature and clinical settings [21]. It is easy to use within clinical practice to follow patients with hip OA over time and is suitable to use in research as a disease-specific questionnaire [21].

\section{Conclusions}

This study found that greater CSA of hip adductors was associated with better function and quality of life in individuals with mild-to-moderate hip OA. Furthermore, a similar trending association was found between hip flexor CSA and quality of life. These findings, while need to be tested in clinical trials, suggest that targeting hip adductor and flexor muscles may have a beneficial effect on improving function and quality of life in those with mild-to-moderate hip OA.

\section{Supplementary information}

Supplementary information accompanies this paper at https://doi.org/10. 1186/s12891-020-03348-5.

Additional file 1: Table S1. Relationship between hip muscle crosssectional area and HOOS outcomes. Table S2. Fat infiltration of hip muscles.

\section{Abbreviations \\ CSA: Cross-sectional area; OA: Osteoarthritis; HOOS: Hip Disability and Osteoarthritis Outcome Score; BMI: Body mass index; Cl: Confidence interval}

\section{Acknowledgements}

The authors wish to thank Dr. Aderson Loureiro and the participants for their support with this study.

\section{Authors' contributions}

$M C, R B, F M C$, and YW contributed to the conception and design of the work. $M C, A Y, S M H, A E W, D U, R B, B K$, and YW contributed to data acquisition. WLP, $A Y$, and $Y W$ performed statistical analysis and drafted the manuscript. All authors contributed to analysis and interpretation of data for the work, and reviewed the manuscript critically for important intellectual content. All authors have read and approved the manuscript. All authors had full access to all the data and take responsibility for the integrity of the data and the accuracy of the data analysis. 


\section{Funding}

$M C$ is the recipient of a National Health Medical Research Council (NHMRC) Postgraduate Research Scholarship under Grant (APP1039843) and Fellowship Fund Branch GWQ Inc. Commemorative Fellowships. SMH is the recipient of NHMRC Early Career Fellowship (APP1142198). AEW and YW are the recipients of NHMRC Translating Research into Practice Fellowship (APP1150102 and APP1168185, respectively). DU is the recipient of NHMRC Career Development Fellowship (Level 2, APP1142809). The funders were not involved in the design and conduct of the study; collection, management, analysis and interpretation of the data; preparation, review, or approval of the manuscript; and decision to submit the manuscript for publication.

\section{Availability of data and materials}

The datasets used and/or analysed during the current study are available from the corresponding author on reasonable request.

\section{Ethics approval and consent to participate}

Ethical approval was granted by Griffith University Human Research Ethics Committee, Queensland Health, Health and Medical Research Human Research Ethics Committee, and Monash University Human Research Ethics Committee, and all participants provided written informed consent prior to commencement of the study.

\section{Consent for publication}

Not applicable.

\section{Competing interests}

The authors declare that they have no competing interests.

\section{Author details}

'School of Public Health and Preventive Medicine, Monash University, $553 \mathrm{St}$ Kilda Rd, Melbourne, VIC 3004, Australia. ${ }^{2}$ School of Allied Health, Faculty of Health Sciences, Australian Catholic University, Banyo, Brisbane, Queensland 4014, Australia. ${ }^{3}$ School of Allied Health Sciences and Menzies Health Institute Queensland, Griffith University, Gold Coast Campus, Gold Coast, Queensland 4222, Australia. ${ }^{4}$ Qscan Radiology Clinics, Brisbane, Queensland, Australia.

Received: 14 January 2020 Accepted: 14 May 2020

Published online: 21 May 2020

\section{References}

1. GBD 2015 DALYs and HALE Collaborators. Global, regional, and national disability-adjusted life-years (DALYs) for 315 diseases and injuries and healthy life expectancy (HALE), 1990-2015: a systematic analysis for the Global Burden of Disease Study 2015. Lancet. 2016;388(10053):1603-58.

2. Murphy LB, Helmick CG, Schwartz TA, Renner JB, Tudor G, Koch GG, et al. One in four people may develop symptomatic hip osteoarthritis in his or her lifetime. Osteoarthr Cartil. 2010;18(11):1372-9.

3. Zhang Y, Jordan JM. Epidemiology of osteoarthritis. Rheum Dis Clin N Am. 2008:34(3):515-29.

4. Zhang W, Moskowitz RW, Nuki G, Abramson S, Altman RD, Arden N, et al. OARSI recommendations for the management of hip and knee osteoarthritis, part II: OARSI evidence-based, expert consensus guidelines. Osteoarthr Cartil. 2008;16(2):137-62.

5. Neptune RR, McGowan CP. Muscle contributions to whole-body sagittal plane angular momentum during walking. J Biomech. 2011;44(1):6-12.

6. Yoshio M, Murakami G, Sato T, Sato S, Noriyasu S. The function of the psoas major muscle: passive kinetics and morphological studies using donated cadavers. J Orthop Sci. 2002;7(2):199-207.

7. Maughan RJ, Nimmo MA. The influence of variations in muscle fibre composition on muscle strength and cross-sectional area in untrained males. J Physiol. 1984;351:299-311.

8. Maughan RJ, Watson JS, Weir J. Strength and cross-sectional area of human skeletal muscle. J Physiol. 1983;338:37-49.

9. Loureiro A, Mills PM, Barrett RS. Muscle weakness in hip osteoarthritis: a systematic review. Arthritis Care Res (Hoboken). 2013;65(3):340-52

10. Loureiro A, Constantinou M, Diamond LE, Beck B, Barrett R. Individuals with mild-to-moderate hip osteoarthritis have lower limb muscle strength and volume deficits. BMC Musculoskelet Disord. 2018;19(1):303.
11. Loureiro A, Constantinou M, Beck B, Barrett RS, Diamond LE. A 12-month prospective exploratory study of muscle and fat characteristics in individuals with mild-to-moderate hip osteoarthritis. BMC Musculoskelet Disord. 2019;20(1):283.

12. Constantinou M, Loureiro A, Carty C, Mills P, Barrett R. Hip joint mechanics during walking in individuals with mild-to-moderate hip osteoarthritis. Gait Posture. 2017:53:162-7.

13. Higgs JP, Saxby DJ, Constantinou M, Loureiro A, Hoang H, Diamond LE, et al. Individuals with mild-to-moderate hip osteoarthritis exhibit altered pelvis and hip kinematics during sit-to-stand. Gait Posture. 2019;71:267-72.

14. Zacharias A, Pizzari T, Semciw Al, English DJ, Kapakoulakis T, Green RA. Comparison of gluteus medius and minimus activity during gait in people with hip osteoarthritis and matched controls. Scand J Med Sci Sports. 2019; 29(5):696-705.

15. Thorborg K, Serner A, Petersen J, Madsen TM, Magnusson P, Holmich P. Hip adduction and abduction strength profiles in elite soccer players: implications for clinical evaluation of hip adductor muscle recovery after injury. Am J Sports Med. 2011;39(1):121-6.

16. Crow JF, Pearce AJ, Veale JP, VanderWesthuizen D, Coburn PT, Pizzari T. Hip adductor muscle strength is reduced preceding and during the onset of groin pain in elite junior Australian football players. J Sci Med Sport. 2010;13(2):202-4.

17. Amaro A, Amado F, Duarte JA, Appell HJ. Gluteus medius muscle atrophy is related to contralateral and ipsilateral hip joint osteoarthritis. Int J Sports Med. 2007;28(12):1035-9.

18. Mahomed NN, Arndt DC, McGrory BJ, Harris WH. The Harris hip score: comparison of patient self-report with surgeon assessment. J Arthroplast. 2001;16(5):575-80.

19. Auleley GR, Giraudeau B, Dougados M, Ravaud P. Radiographic assessment of hip osteoarthritis progression: impact of reading procedures for longitudinal studies. Ann Rheum Dis. 2000;59(6):422-7.

20. Altman RD, Gold GE. Atlas of individual radiographic features in osteoarthritis, revised. Osteoarthritis Cartilage. 2007;15(Suppl A):A1-56.

21. Nilsdotter AK, Lohmander LS, Klassbo M, Roos EM. Hip disability and osteoarthritis outcome score (HOOS)--validity and responsiveness in total hip replacement. BMC Musculoskelet Disord. 2003;4:10.

22. Arokoski MH, Arokoski JP, Haara M, Kankaanpaa M, Vesterinen M, Niemitukia $\mathrm{LH}$, et al. Hip muscle strength and muscle cross sectional area in men with and without hip osteoarthritis. J Rheumatol. 2002;29(10):2185-95.

23. Zacharias A, Pizzari T, English D, Kapakoulakis T, Green RA. Hip abductor muscle volume in hip osteoarthritis and matched controls. Osteoarthr Cartil. 2016;24(10):1727-35.

24. Zacharias A, Green RA, Semciw A, English DJ, Kapakoulakis T, Pizzari T. Atrophy of hip abductor muscles is related to clinical severity in a hip osteoarthritis population. Clin Anat. 2018;31(4):507-13.

25. Grimaldi A, Richardson C, Stanton W, Durbridge G, Donnelly W, Hides J. The association between degenerative hip joint pathology and size of the gluteus medius, gluteus minimus and piriformis muscles. Man Ther. 2009;14(6):605-10.

26. Grimaldi A, Richardson C, Durbridge G, Donnelly W, Darnell R, Hides J. The association between degenerative hip joint pathology and size of the gluteus maximus and tensor fascia lata muscles. Man Ther. 2009;14(6):611-7.

27. Zhang W, Doherty M, Arden N, Bannwarth B, Bijlsma J, Gunther KP, et al. EULAR evidence based recommendations for the management of hip osteoarthritis: report of a task force of the EULAR standing Committee for International Clinical Studies Including Therapeutics (ESCISIT). Ann Rheum Dis. 2005;64(5):669-81.

28. Roddy E, Zhang W, Doherty M, Arden NK, Barlow J, Birrell F, et al. Evidencebased recommendations for the role of exercise in the management of osteoarthritis of the hip or knee--the MOVE consensus. Rheumatology (Oxford). 2005;44(1):67-73.

29. Conaghan PG, Dickson J, Grant RL. Care and management of osteoarthritis in adults: summary of NICE guidance. Bmj. 2008;336(7642):502-3.

30. Klausmeier V, Lugade V, Jewett BA, Collis DK, Chou LS. Is there faster recovery with an anterior or anterolateral THA? A pilot study. Clin Orthop Relat Res. 2010;468(2):533-41.

31. Pons C, Borotikar B, Garetier M, Burdin V, Ben Salem D, Lempereur M, et al. Quantifying skeletal muscle volume and shape in humans using MRI: a systematic review of validity and reliability. PLoS One. 2018;13(11):e0207847.

\section{Publisher's Note}

Springer Nature remains neutral with regard to jurisdictional claims in published maps and institutional affiliations. 


\section{University Library}

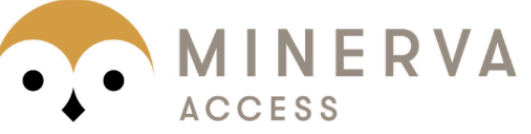

A gateway to Melbourne's research publications

Minerva Access is the Institutional Repository of The University of Melbourne

Author/s:

Peiris, WL;Cicuttini, FM;Constantinou, M;Yaqobi, A;Hussain, SM;Wluka, AE;Urquhart, D;Barrett, R;Kennedy, B;Wang, Y

Title:

Association between hip muscle cross-sectional area and hip pain and function in individuals with mild-to-moderate hip osteoarthritis: a cross-sectional study.

Date:

2020-05-21

Citation:

Peiris, W. L., Cicuttini, F. M., Constantinou, M., Yaqobi, A., Hussain, S. M., Wluka, A. E., Urquhart, D., Barrett, R., Kennedy, B. \& Wang, Y. (2020). Association between hip muscle cross-sectional area and hip pain and function in individuals with mild-to-moderate hip osteoarthritis: a cross-sectional study.. BMC Musculoskeletal Disorders, 21 (1), pp.316-316. https://doi.org/10.1186/s12891-020-03348-5.

Persistent Link:

http://hdl.handle.net/11343/277686

License:

CC BY 